\title{
Group A Rotavirus G1P[6] Associated Fatalities in Diarrheic Nigerian Infants, Possible Impact of Enterovirus Environmental Enteric Dysfunction, and Implications for Rota-Vaccinology
}

\author{
Michael Oluyemi Babalola1,2(1) \\ ${ }^{1}$ Infectious Diseases Epidemiology, Virology and Special Pathogens \\ Research. Department of Microbiology, Adekunle Ajasin University, \\ Ondo State, Nigeria \\ ${ }^{2}$ Department of Virology, Faculty of Basic Medical Sciences, College \\ of Medicine, University of Ibadan, Ibadan Nigeria
}

\begin{abstract}
Address for correspondence Michael Oluyemi Babalola, PhD, Infectious Diseases Epidemiology, Virology and Special Pathogens Research, Department of Microbiology, Adekunle Ajasin University, P. M.B. 001, Akungba Akoko, Ondo state, Nigeria (e-mail: michael.babalola@aaua.edu.ng).
\end{abstract}

J Child Sci 2020;10:e110-e118.

\begin{abstract}
Keywords

- Nigerian

- infant

- G1P[6]

- mortality

- group A rotavirus

- enterovirus EED

Group A rotavirus (RVA) diarrhea disease and mortality are yet unabated, particularly in developing countries. As global knowledge of specific strains associated with infant mortality is crucial for successful vaccination efforts, candidate RVA strains detected in mortality and fatal cases of severely diarrheic hospitalized infants in Akure, Nigeria were investigated.

Fecal samples from comatose patients were tested for RVAs, other diarrhea viruses, and enteric bacterial pathogens. Genomic dsRNA was extracted from $10 \%$ rotavirus positive stool suspension, the VP4 and VP7 genes were reverse transcribed and amplified by onestep reverse transcription polymerase chain reaction (PCR) and genotyped by seminested multiplex PCR. Amplicons were sequenced, aligned by ClustalW, and phylogenetic analyses were conducted in MEGA6. Sequences data were deposited to GenBank and DDBJ.

Medical examination and microbiological analyses upheld viral diarrhea. ElA revealed RVA and enterovirus. PCR identified virulent RVA strain GIP[6] whose VP7 nucleotide sequences shared a common cluster with Cuban isolate G1P[6], while the VP4 P[6] sequences were related to Asian strains. Reassortant RVA G1P[6] was found in fatal diarrhea cases and mortality of a Nigerian child. RVA coinfection with enterovirus and associated biomarkers of environmental enteric dysfunction in infantile diarrhea should henceforth be evaluated. Current rotavirus vaccines may fare badly against the prevailing virulent strains. The disease severity and outcome necessitates a wider epidemiological study, a review and inclusion of the $\mathrm{P}[6]$ genotype in future rotavirus vaccines.
\end{abstract}

\section{Introduction}

In the low- and middle-income countries, it was estimated that diarrheal diseases resulted in 424,000 deaths of under 5- received

October 11, 2019

accepted after revision

July 10,2020
DOI https://doi.org/

$10.1055 / \mathrm{s}-0040-1716374$. ISSN 2474-5871. year-old children in 2017, making diarrhea the fourth leading cause of infant death after prematurity, birth trauma, and pneumonia. ${ }^{1}$ Control of diarrheal diseases is complicated by
Copyright @ 2020 Georg Thieme Verlag License terms KG Stuttgart · New York
()(1) 
the fact that there are 10 different pathogens that together are responsible for the vast majority of cases. ${ }^{2}$ The rotavirus remains the major global cause of diarrhea-associated morbidity and mortality in under 5-year-old children, and was responsible for almost 260 million episodes of diarrhea and $30 \%$ of all diarrhea-related mortality in $2016 .{ }^{3}$ In the developing countries, it was estimated that 500,000 to 870,000 deaths occur annually because of severe dehydrating diarrhea caused by human rotaviruses with 150,000 to 200,000 deaths occurring in children below 5 years of age in Africa. ${ }^{4}$ Earlier global breakup of estimated annual infant mortality due to rotavirus gastroenteritis showed that India had 100,800 , followed by China with 34,553 , Nigeria with 32,802 , Pakistan with 25,158 , Ethiopia and Congo with 19,950 each, and Tanzania with 14 deaths in $2003 .{ }^{5}$ As at 2009, it was estimated that approximately 50,000 rotavirus deaths occur annually in Nigeria, thereby indicating an increase over the 2003 report. $^{6}$ This trend continues as it was reported by World Health Organization that Nigeria in 2013 was the second country with the highest number of rotavirus-associated mortality of under 5-year-old children in Africa.

Among the ten causes of diarrhea, rotavirus is the only one for which there is vaccine, although tempered with drawbacks and withdrawals. ${ }^{7}$ In addition, oral rotavirus vaccine failures have been ascribed to complications by enterovirus-associated environmental enteric dysfunction (EED) widely reported in $80 \%$ of Bangladeshi infants with rotavirus, unresolved diarrhea, and mortality even after rotavirus vaccination. ${ }^{8,9}$ Group A rotavirus diarrhea (RVA) disease remains a worldwide problem, particularly in developing countries. Recently, India, Nigeria, Pakistan, and Democratic Republic of Congo were estimated to have contributed approximately half $(49 \%)$ of the global infant rotavirus death in year 2013. ${ }^{10}$ Yet, of these numerous infant mortalities from RVA diarrhea, no single studyparticularly in Nigeria ${ }^{11-19}$-have specified a genotype or provided the DNA sequences of such strain encountered in the mortality of any child. Therefore, to fill this existing gap, the mortality of a 9-month-old infant and a cohort of hospitalized children with fatal disease who fell comatose and required emergency intravenous rehydration and oxygen resuscitation during a 2-year hospital-based rotavirus diarrhea research in Nigeria were selected and investigated, to specifically elucidate the molecular identities of the candidate RVA strains that were associated with the morbidity and mortality.

\section{Materials and Methods}

\section{Ethical Approval}

Ethical approval was obtained from the University of Ibadan Institutional Review Board and permissions were granted by the respective ethical committee of the study centers. Similarly, fecal specimens were collected from the respondents who met the inclusion criteria after obtaining verbal consent from the parents.

\section{Patients and Materials}

In this hospital-based, cross-sectional, and descriptive study, diarrheal fecal specimens were obtained once from infants and young children aged between 0 and 60 months, who presented at outpatient clinics or were admitted into wards, at the State Specialists Hospital for acute diarrheal illness between October 2012 and September 2014 in Akure, Nigeria. In addition to meeting the inclusion criteria, a cohort of hospitalized children with fatal disease who fell comatose and required emergency intravenous rehydration and oxygen resuscitation were selected to investigate the associated rotavirus genotype. The specimens were transported on ice and stored at $-20^{\circ} \mathrm{C}$ until tested at the Department of Virology, College of Medicine University of Ibadan.

\section{Testing for Enteric Viruses and Other Diarrhea Pathogens}

Prior to coma, the stool specimens of all the selected cohorts with emergency intravenous rehydration and oxygen resuscitation were obtained for laboratory investigation including virological, bacteriological, and amoebic dysentery examinations. Each fecal specimen was processed for the detection of rotavirus, adenovirus, astrovirus, and norovirus antigens using a fourth generation Rota + Adeno + Astro + Noro Rapid EIA Combo kit as well as enterovirus, hepatitis A virus, cryptosporidium, and giardia according to the manufacturer's instructions as previously reported. ${ }^{20}$ The rotavirus-positive samples were processed into $10 \%$ suspensions and subjected to $\mathrm{G}$ and $\mathrm{P}$ genotyping assays.

\section{Preparation of Stool Suspension and Extraction of Rotavirus Double Stranded RNA Genome}

The rotavirus-positive fecal samples were prepared as $10 \%(\mathrm{v} /$ v) suspensions in sterile phosphate buffered saline $(\mathrm{pH}=7.2)$ mixed thoroughly and clarified by centrifugation at $3,000 \mathrm{~g}$ for 20 minutes at $4^{\circ} \mathrm{C} .^{21}$ The resultant supernatants were harvested, divided into $1.8 \mathrm{~mL}$ aliquots, and stored at $-80^{\circ} \mathrm{C}$ until use. The virus dsRNA genome was extracted from $200 \mu \mathrm{L}$ fecal suspension by spin column technology using the total RNA purification kit (Jena Bioscience GmbH, Jena Germany) according to the manufacturer's instructions, and subjected to molecular assays for RVA genotype characterization.

\section{Reverse Transcription and Amplification of the VP7 Gene Segment of Rotavirus dsRNA Genome by One- Step Reverse Transcription Polymerase Chain Reaction} The first-round one-step reverse transcription and amplification of the dsRNA genome targeting the full length (1062 bp) VP7 gene segment nine encoding the VP7 glycoprotein was performed using the invitrogen one-step RT-PCR reagent kit (Invitrogen Life Technologies, Carlsbad, California, United States) in a GeneAmp Thermal cycler. To a reaction mixture containing $25 \mu \mathrm{L}$ of $2 \times$ invitrogen PCR reaction mix (consisting of a proprietary buffer system containing $0.4 \mathrm{mM}$ of each dNTP, $6 \mathrm{mM} \mathrm{MgSO}_{4}$, and stabilizers) was added reagent mix consisting of $1 \mu \mathrm{L}$ each of 20 pmol sBeg9 and RVG9 primers ( - Table 1), $16.5 \mu \mathrm{L}$ PCR grade water, $0.5 \mu \mathrm{L} 50 \mathrm{mM} \mathrm{MgSO}_{4}, 1 \mu \mathrm{L}$ M-MLV SuperScript III 
Table 1 Primer sequences for first-round one-step reverse transcription polymerase chain reaction, and second-round seminested multiplex polymerase chain reaction for rotavirus typing: VP7 G and VP4 P

\begin{tabular}{|c|c|c|c|c|c|}
\hline $\begin{array}{l}\text { Polymerase chain } \\
\text { reaction assay }\end{array}$ & Primers & Nucleotide sequence $\left(5^{\prime}-3^{\prime}\right)$ & $\begin{array}{l}\text { Position on } \\
\text { gene (Nt) }\end{array}$ & $\begin{array}{l}\text { Amplicon } \\
\text { (bp) }\end{array}$ & $\begin{array}{l}\text { Primer } \\
\text { set }^{\mathrm{a}}\end{array}$ \\
\hline & sBeg9 forward $(+)$ & GGC TTT AAA AGA GAG AAT TTC & $1-21$ & 944 & \\
\hline & Anchor primer RVG9 & GGT CAC ATC ATA CAA TTC T & $1,062-1,044$ & 1,062 & \\
\hline \multirow{13}{*}{$\begin{array}{l}\text { Second round } \\
\text { G-typing }\end{array}$} & aBT1 for G1 & CAA GTA CTC AAA TCA ATG ATG G & $314-335$ & 749 & A \\
\hline & $\mathrm{aCT} 2$ for $\mathrm{G} 2$ & CAA TGA TAT TAA CAC ATT TTC TGT G & $411-435$ & 652 & A \\
\hline & aET3 for G3 & CGT TTG AAG AAG TTG CAA CAG & $689-709$ & $299 / 374$ & A \\
\hline & aDT4 for G4 & CGT TTC TGG TGA GGA GTT G & $480-498$ & 583 & A \\
\hline & aAT8 for G8 & GTC ACA CCA TTT GTA AAT TCG & $178-198$ & 885 & A \\
\hline & aFT9 for G9 & CTA GAT GTA ACT ACA ACT AC & $757-776$ & $231 / 306$ & A \\
\hline & aFT5 for G5 & GAC GTA ACA ACG AGT ACA TG & $779-760$ & 780 & B \\
\hline & aDT6 for G6 & GAT TCTACA CAG GAA CTA G & $499-481$ & 500 & B \\
\hline & $\mathrm{mG} 10$ for $\mathrm{G} 10$ & ATG TCA GAC TAC ARA TAC TGG & $666-687$ & 276 & B \\
\hline & aBT11 for G11 & GCA ACT CAG ATT GCT GAT GAC & $336-316$ & 337 & B \\
\hline & G12 for $\mathrm{G} 12$ & CCG ATG GAC GTA ACG TTG TA & $548-567$ & 394 & B \\
\hline & $\begin{array}{l}\text { Consensus anchor } \\
\text { primer Con3 }\end{array}$ & TGG CTT CGC TCA TTT ATA GAC A & $11-32$ & 876 & \\
\hline & $\begin{array}{l}\text { Consensus anchor } \\
\text { primer, Con2 }\end{array}$ & ATT TCG GAC CT TTA TAA CC & $868-887$ & 887 & \\
\hline \multirow{9}{*}{$\begin{array}{l}\text { Second round } \\
\text { P-typing }\end{array}$} & 2T-1 for $\mathrm{P}[4]$ & CTA TTG TTA GAG GTT AGA GTC & $474-494$ & 484 & C \\
\hline & $3 T-1$ for $P[6]$ & TGT TGA TTA GTT GGA TTC AA & $259-278$ & 267 & C \\
\hline & $1 \mathrm{~T}-1$ for $\mathrm{P}[8]$ & TCT ACT TGG ATA ACG TGC & $339-356$ & 345 & C \\
\hline & 4T-1 for $\mathrm{P}[9]$ & TGA GAC ATG CAA TTG GAC & $385-402$ & 391 & $\mathrm{C}$ \\
\hline & $5 T-1$ for $P[10]$ & ATC ATA GTT AGT AGT CGG & $575-594$ & 594 & C \\
\hline & $\mathrm{mP}[11]$ for $\mathrm{P}[11]$ & GTA AAC ATC CAG AAT GTG & $305-323$ & 312 & C \\
\hline & $\mathrm{p} 4943$ for $\mathrm{P}[14]$ & GGT GTA GTT CCT GCG TA & $538-554$ & 546 & $\mathrm{C}$ \\
\hline & pUK for P[5] & GCC AGG TGT CGC ATC AGA G & $336-354$ & 555 & $\mathrm{D}$ \\
\hline & pOSU for P[7] & СTT TAT CGG TGG AGA ATA CGT CAC & $389-412$ & 502 & $\mathrm{D}$ \\
\hline
\end{tabular}

LEGEND: $\mathrm{R}=\mathrm{A}$ or $\mathrm{G}$. Group A reactions consist of primer set $\mathrm{A} .{ }^{24}$ Group $\mathrm{B}$ reactions consist of primer set $\mathrm{B} .{ }^{25}$ Group $\mathrm{C}$ and $\mathrm{D}$ reactions consist of primer sets $C$ and $D$, respectively. ${ }^{22,26}$

$\mathrm{a}=\mathrm{A}$ total of 24 oligonucleotide primers utilized in this study were synthesized by Eurofins MWG Synthesis GmbH, Ebersberg Germany, and the lyophilized stocks were reconstituted with nuclease-free water according to the manufacturer' specifications for the downstream polymerase chain reaction applications.

reverse transcriptase/platinum Taq DNA polymerase enzyme mix, and $5 \mu \mathrm{L}$ genomic dsRNA template and maintained on ice. The final reaction volume of $50 \mu \mathrm{L}$ was mixed thoroughly by gentle flicking and applied to the Thermocycler. The reaction was conducted at an initial reverse transcription step of $50^{\circ} \mathrm{C}$ for 15 minutes, followed by PCR activation at $95^{\circ} \mathrm{C}$ for 2 minutes, 40 cycles of PCR amplification (denaturation at $94^{\circ} \mathrm{C}$ for 30 seconds, annealing at $45^{\circ} \mathrm{C}$ for 45 seconds, extension at $72^{\circ} \mathrm{C}$ for 1 minute), a final extension at $72^{\circ} \mathrm{C}$ for 7 minutes, and held at $4^{\circ} \mathrm{C}$. The synthesized dsDNA amplicons of the target sequence were then utilized as template in the second round seminested multiplex PCR for G-genotyping each of the detected amplified rotaviruses. ${ }^{22,23}$
VP7 Genotype Characterization of Group A Rotavirus by Seminested Multiplex Polymerase Chain Reaction The VP7 G-typing assays were conducted on the synthesized first-round amplicons of the detected rotaviruses using a consensus anchor primer RVG9 along with type specific cocktail of primers as previously described. ${ }^{22,24,25}$ We assayed separately for the genotypes of each of the isolated first-round amplicons, using a cocktail of primers ( - Table 1 ) set $\mathrm{A}(0.5 \mu \mathrm{L}$ of 20 pmol each of: RVG9, aBT1, aCT2, aET3, aDT4, aAT8, and aFT9), $15.5 \mu \mathrm{L}$ PCR grade water (Jena Bioscience GmbH, Jena Germany), and $1 \mu \mathrm{L}$ first-round PCR amplicon in reaction $A$, and cocktail of primers ( - Table 1 ) set $\mathrm{B}(0.5 \mu \mathrm{L}$ of 20 pmol each of: RVG9, aFT5, aDT6, mG10, aBT11, and G12), $16 \mu \mathrm{L}$ PCR grade water, and $1 \mu \mathrm{L}$ first-round PCR 
amplicon in reaction $B$. In group A and B reactions, seminested PCR amplification was performed in a $25-\mu \mathrm{L}$ reaction volume in TreffLab PCR tubes containing $5 \mu \mathrm{L} 5 \times$ Red Load Taq Master High Yield PCR Mix (master mix of thermostable DNA polymerase, dATP, dCTP, dGTP, dTTP, $\mathrm{KCl}, \mathrm{MgCl}_{2}$, red dye, gel-loading buffer, and stabilizers; Jena Bioscience $\mathrm{GmbH}$, Jena Germany), as enumerated above. The tube content was mixed thoroughly by gentle flicking, applied to the thermal cycler and PCR was performed by PCR activation at $94^{\circ} \mathrm{C}$ for 2 minutes, 40 cycles of PCR amplification involving denaturation at $94^{\circ} \mathrm{C}$ for 1 minute, annealing at $45^{\circ} \mathrm{C}$ for 45 seconds, extension at $72^{\circ} \mathrm{C}$ for 1 minute, and a final extension at $72^{\circ} \mathrm{C}$ for 7 minutes in MRS Genemate thermal cycler and held at $4^{\circ}$ C. At the end of the PCR cycle, the second-round multiplex DNA amplicons were retrieved and analyzed by gel electrophoresis for subsequent identification and documentation of the VP7 genotypes.

\section{Reverse Transcription and Amplification of the VP4 Gene Segment of Rotavirus dsRNA Genome by One-} Step Reverse Transcription Polymerase Chain Reaction The first-round one-step reverse transcription and amplification of the dsRNA genome targeting the VP4 gene segment (876bp) was performed using the invitrogen one-step RTPCR reagent kit (Invitrogen Life Technologies, Carlsbad, California, United States) in a GeneAmp thermal cycler. To a reaction mixture containing $25 \mu \mathrm{L}$ of $2 \times$ invitrogen PCR reaction mix (consisting of a proprietary buffer system containing $0.4 \mathrm{mM}$ of each dNTP, $6 \mathrm{mM} \mathrm{MgSO}_{4}$, and stabilizers) was added a reagent mix consisting of $1 \mu \mathrm{L}$ each of 20 pmol Con3 and Con2 primers (-Table 1), $16.5 \mu \mathrm{L}$ PCR grade water, $0.5 \mu \mathrm{L} 50 \mathrm{mM} \mathrm{MgSO}_{4}, 1 \mu \mathrm{L}$ M-MLV SuperScript III Reverse Transcriptase/Platinum Taq DNA polymerase enzyme mix, and $5 \mu \mathrm{L}$ genomic dsRNA template, and maintained on ice. The final reaction volume of $50 \mu \mathrm{L}$ was mixed thoroughly by gentle flicking and applied to the Thermocyler. The reaction was conducted at an initial reverse transcription step at $50^{\circ} \mathrm{C}$ for 15 minutes, followed by PCR activation at $95^{\circ} \mathrm{C}$ for 2 minutes, 40 cycles of PCR amplification (denaturation at $94^{\circ} \mathrm{C}$ for 30 seconds, annealing at $45^{\circ} \mathrm{C}$ for $45 \mathrm{sec}-$ onds, and extension at $72^{\circ} \mathrm{C}$ for 1 minute), a final extension at $72^{\circ} \mathrm{C}$ for 7 minutes, and held at $4^{\circ} \mathrm{C}$. The synthesized dsDNA amplicons of the target sequence were then utilized as template in the second-round seminested multiplex PCR for P-genotyping each of the detected amplified rotaviruses. $^{22}$

\section{VP4 Genotype Characterization of Group A Rotavirus by Seminested Multiplex PCR}

The VP4 P-typing assay was conducted on the synthesized first-round amplicons of the detected rotavirus using a consensus anchor primer Con3 or Con2 along with type specific cocktail of primers as previously described. ${ }^{22,25,26}$ We assayed separately for the P-genotype of each of the isolated first-round amplicons, using a cocktail of primers ( - Table 1) set C $(0.5 \mu \mathrm{L}$ of 20 pmol each of: Con3, $1 \mathrm{~T}-1,2 \mathrm{~T}-1$, 3T-1, 4T-1, 5T-1, mP[11], p4943), $15 \mu \mathrm{L}$ PCR grade water (Jena Bioscience $\mathrm{GmbH}$, Jena Germany) and $1 \mu \mathrm{L}$ of first- round PCR amplicon in reaction $C$, while cocktail of primers (-Table 1) set D $(0.5 \mu \mathrm{L}$ of 20 pmol each of: Con2, pUK, and pOSU), $17.5 \mu \mathrm{L}$ PCR grade water, and $1 \mu \mathrm{L}$ of first-round PCR amplicon were utilized in reaction $D$. In group $C$ and $D$ reactions, seminested PCR amplifications were performed in a $25 \mu \mathrm{L}$ reaction volume in TreffLab PCR tubes containing 5 $\mu \mathrm{L} 5 \times$ Red Load Taq Master High Yield PCR Mix (master mix of thermostable DNA polymerase, dATP, dCTP, dGTP, dTTP, $\mathrm{KCl}, \mathrm{MgCl}_{2}$, red dye, gel-loading buffer, and stabilizers; Jena Bioscience $\mathrm{GmbH}$, Jena Germany), with the reaction constituents as enumerated above. The tube contents were mixed thoroughly by gentle flicking, applied to the thermal cycler, and PCR was performed by PCR activation at $94^{\circ} \mathrm{C}$ for 2 minutes, 40 cycles of PCR amplification involving Denaturation at $94^{\circ} \mathrm{C}$ for 1 minute, annealing at $45^{\circ} \mathrm{C}$ for 1 minute, extension at $72^{\circ} \mathrm{C}$ for 1 minute, and a final extension at $72^{\circ} \mathrm{C}$ for 7 minutes in MRS Genemate Thermal cycler, and held at $4^{\circ} \mathrm{C}$. At the end of the PCR cycle, the second-round multiplex DNA amplicons were retrieved and analyzed by gel electrophoresis for subsequent identification and documentation of the VP4 genotypes. ${ }^{22,26}$

\section{Gel Electrophoresis and Documentation of the Multiplex PCR Amplicons for Determination of the Rotavirus VP7 and VP4 Genotypes}

The second round multiplex PCR products $(8 \mu \mathrm{L}$ of each amplicon) were resolved by gel electrophoresis at $120 \mathrm{~V}$ for 60 minutes in $1.5 \%$ agarose gels containing $5 \mu \mathrm{L}$ of $0.5 \mu \mathrm{g}$ ethidium bromide/mL along with $5 \mu \mathrm{L} 100$ bp DNA ladder molecular weight standard (Jena Bioscience $\mathrm{GmbH}$, Jena Germany) using freshly prepared $1 \times$ tris boric ethylene diamine tetra acetic acid for agarose preparation and running buffer. At the end of each run, the gels were retrieved, and the resultant bands were visualized under ultraviolet light with the Bio-Rad Alpha Imager, annotated, and photo documented. The specific G- and P- genotypes were determined by the electrophoretic mobility bands, and sizes (bp) of the amplicons in comparison to the molecular weight DNA ladder. $^{22}$

\section{Nucleotide Sequencing of VP7 and VP4 Genotypes and Phylogenetic Analysis of the Isolate}

The generated second-round seminested amplification products of the full-length VP7 genes of the G1 genotype and $P[6]$ strains were selected for nucleotide sequencing, and investigation of their evolutionary relationships to those of other strains circulating in different regions of the world. The amplicons were shipped to Macrogen Inc, Seoul, South Korea, for purification and sequencing of the VP7 and VP4 genes using the Big-Dye terminator cycle sequencing kit with the respective specific genotyping primers aBT1 for $\mathrm{G} 1$ and $3 \mathrm{~T}-1$ for $\mathrm{P}[6]$ in the forward direction. The generated query sequences were extracted and edited using the DNA Baser and MEGA 6 software, queried to the GeneBank Database by BLAST (www.ncbi. nlm.nih.gov/blast) to retrieve reference sequences of the rotavirus genotypes, and aligned using the ClustalW program in MEGA 6 software with default settings. ${ }^{27}$ 
Phylogenetic analyses were performed on the partial VP7 and VP4 sequences, and the dendrograms with 1,000 bootstrap replicates of the sequence alignment datasets were constructed using the neighbor-joining method while pairwise distances of the sequences were estimated using MEGA 6 software with Kimura-2 parameter model. ${ }^{27}$

\section{Submission of the Nucleotide Sequences to the GenBank}

The nucleotide sequences of the virulent rotavirus strains reported in this study were trimmed and edited using the BioEdit tool. The sequences were annotated and submitted to the GenBank Nucleotide Sequence Database using the online BankIt tool, or the DNA Database of Japan.

\section{Results}

Patient' Case history, Rotavirus Diarrhea, Antigen Detection, Associated Mortality by G1P[6] Strain, Sequencing Confirmation, and Phylogenetic Analysis Immediately upon returning from a village, a 9-month-old child (HAK15) developed acute gastroenteritis with nausea, vomiting, weakness, and severe diarrhea sought medical care in November 2012 at Akure, Nigeria. After 5 days of passing watery stools as reported by the mother, progressive dehydration necessitated hospitalization. One (HAK18) of the fatal cases, a 5-month-old female also had travel history for a celebration and all the children were significantly dehydrated and fell comatose, thereby necessitating intravenous rehydration therapy and oxygen resuscitation at the hospital.

Clinical signs and symptoms indicated severe, nonbloody, non-copious, non-foamy sporadic greenish watery diarrhea, vomiting, loss of skin turgor, sunken eyes, weakness, and coma in all the selected fatal cases. One sample (HAK15) was positive (the red line) for rotavirus and enterovirus antigens combined, while other three were positive for rotavirus only. The four samples tested negative to adenovirus, astrovirus, norovirus, and hepatitis A virus (-Fig. 1A-C), as well as negative microbiological analyses (for shigella, salmonella, Escherichia coli, giardia, and cryptosporidium). Among the selected cohorts that were severely dehydrated, comatose and received intravenous rehydration and oxygen resuscitation, one case (HAK15) failed to intravenous rehydration and oxygen resuscitation subsequent to death, while other critically severe cases were revived. The clinical characteristics, sociodemographic information and epidemiolog- ical data of the investigated cases are briefly presented in - Table 2.

Seminested multiplex PCR assays and gel electrophoresis indicated that the VP7 G-genotype of the virulent strain (HAK15) alongside other isolates in the study were G1 as they produced 749bp that was characteristic of the G1 strain (-Fig. 2). Similarly the VP4 P-genotype revealed P[6] as it produced 267bp (-Fig. 3).

Phylogenetic analysis of the VP7 gene genotype G1 of the mortality virulent strain (RVA/Human-wt/NGR-AKR15/ 2012/G1P[6]) and other G1 strains in this study showed high sequence homology (97-99\%) clustering in lineage IV alongside Cuba, India and Iran, but closely related to a previous G1P[8] Nigerian isolate reported in year 2013 (87\% nucleotide identity). While the virulent study strain carried a VP4 P[6] specificity, the Nigerian 2013 related strain was of common P[8] genotype ( - Fig. 4). Phylogenetic analysis of VP4 gene P[6] genotype of the mortality virulent strain (RVA/Human-wt/NGR-AKR15/2012/G1P[6]) and other $\mathrm{P}[6]$ strains in the study showed high nucleotide sequence homology ( 83 to $85 \%$ ) clustering in lineage II alongside Japan and Russia, but somewhat related to P[6] strain from Japan ( $\sim 83 \%$ nucleotide similarity), than India or Burkina Fasso (-Fig. 5).

\section{Submission of the Nucleotide Sequences to the GenBank and Accession Numbers}

The nucleotide sequences of the virulent rotavirus strains reported in this study have been submitted to Nucleotide Sequence Database under accession numbers MF527008, MF527009, MF527010, MF527020 (GenBank) and LC318675, LC318680, LC318677, LC318681 (DNA databank of Japan, DDBJ).

\section{Discussion}

Rotavirus diarrhea disease and mortality is a recurrent enigma. In consonant with the findings of Yoshiki et al, ${ }^{28}$ the observed severe, non-bloody, non-copious, non-foamy watery diarrhea, vomiting, loss of skin turgor, sunken eyes, weakness, and coma presumptively pointed to viral diarrhea in the participants. Several workers have submitted that rotavirus infections were often severe, while some children passed on subsequently due to improper management of the diarrhea. ${ }^{16}$ The recovery of one of the participants (HAK15) was eventful, as she died at the hospital despite all attempts to resuscitate her. However, all other critical cases were
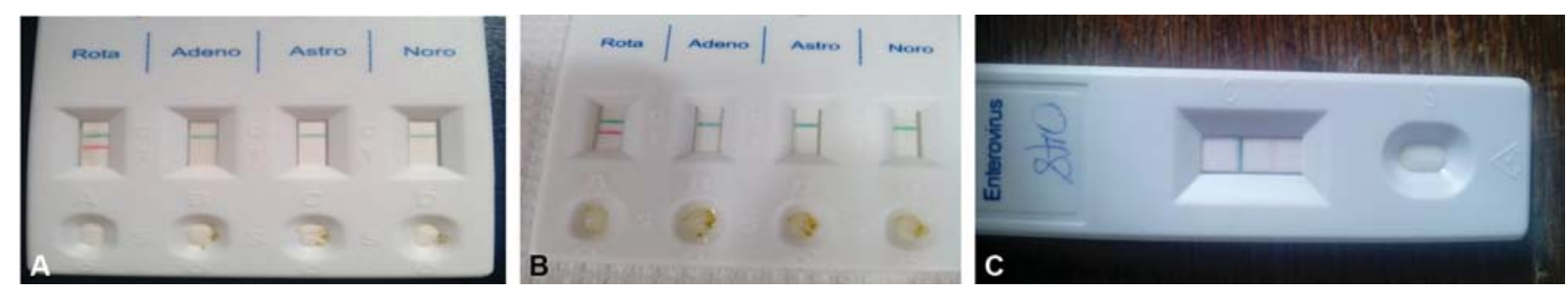

Fig. 1 (A) Rotavirus positive fecal sample (HAK15) on Certest quadruple immunochromatographic EIA. (B) Rotavirus positive fecal sample (HAK18) on Certest quadruple immunochromatographic EIA. (C) Enterovirus positive fecal sample (HAK15) on Certest quadruple immunochromatographic EIA. EIA, enzyme immunoassay. 
Table 2 Social-demographic information, clinical presentations, therapy, and pathogen detection from selected hospitalized under five children investigated for rotavirus strains associated with fatal diarrhea cases in Ondo state, Nigeria

\begin{tabular}{|c|c|c|c|c|}
\hline \multirow{2}{*}{$\begin{array}{l}\text { Social-demographics and clinical characteristics, } \\
\text { therapy, and pathogen detection }\end{array}$} & \multicolumn{4}{|c|}{ Selected investigated cases } \\
\hline & HAK 15 & HAK 18 & HAK 28 & НАК 39 \\
\hline Age (mo) & 9 & 5 & 13 & 9 \\
\hline Gender & Female & Female & Female & Male \\
\hline Travel history from residence & Yes & Yes & $\mathrm{Nil}$ & $\mathrm{Nil}$ \\
\hline $\begin{array}{l}\text { Presence of severe diarrhea (duration of stooling, } \\
\text { days) }\end{array}$ & $\begin{array}{l}\text { Yes, } \\
\text { watery (5) }\end{array}$ & $\begin{array}{l}\text { Yes, } \\
\text { watery (4) }\end{array}$ & $\begin{array}{l}\text { Yes, } \\
\text { watery (2) }\end{array}$ & $\begin{array}{l}\text { Yes, } \\
\text { watery (2) }\end{array}$ \\
\hline Nausea & Yes & Yes & Yes & Yes \\
\hline Vomiting & Yes & Yes & Yes & Yes \\
\hline Body temperatures $\left(\geq 39^{\circ} \mathrm{C}\right)$ & Yes & Yes & Yes & Yes \\
\hline Stool characteristics & $\begin{array}{l}\text { Non-bloody, } \\
\text { non-copious, } \\
\text { non-foamy } \\
\text { and greenish. }\end{array}$ & $\begin{array}{l}\text { Non-bloody, } \\
\text { non-copious, } \\
\text { non-foamy } \\
\text { and greenish. }\end{array}$ & $\begin{array}{l}\text { Non-bloody, } \\
\text { non-copious, } \\
\text { non-foamy } \\
\text { and greenish. }\end{array}$ & $\begin{array}{l}\text { Non-bloody, } \\
\text { non-copious, } \\
\text { non-foamy } \\
\text { and greenish. }\end{array}$ \\
\hline Dehydration & Yes, severe & Yes, severe & Yes, severe & Yes, mild \\
\hline Loss of skin turgor & Yes & Yes & Yes & Yes \\
\hline Sunken eyes & Yes & Yes & Yes & Yes \\
\hline Comatose & Yes & Yes & Yes & Yes \\
\hline Detection of hepatitis A virus & Nil & Nil & Nil & $\mathrm{Nil}$ \\
\hline $\begin{array}{l}\text { Detection of shigella, salmonella, } \\
\text { Escherichia coli }\end{array}$ & Nil & Nil & Nil & $\mathrm{Nil}$ \\
\hline Detection of Giardia and Cryptosporidium & Nil & Nil & Nil & $\mathrm{Nil}$ \\
\hline Administration of intravenous rehydration & Yes & Yes & Yes & Yes \\
\hline $\begin{array}{l}\text { Response to emergency oxygen resuscitation/clinical } \\
\text { outcome }\end{array}$ & Nil/dead & Yes/revived & Yes/revived & Yes/revived \\
\hline $\begin{array}{l}\text { Detection of rotavirus, adenovirus, astrovirus, } \\
\text { norovirus, and enterovirus }\end{array}$ & $\begin{array}{l}\text { Rotavirus and } \\
\text { enterovirus }\end{array}$ & Rotavirus only & Rotavirus only & Rotavirus only \\
\hline
\end{tabular}

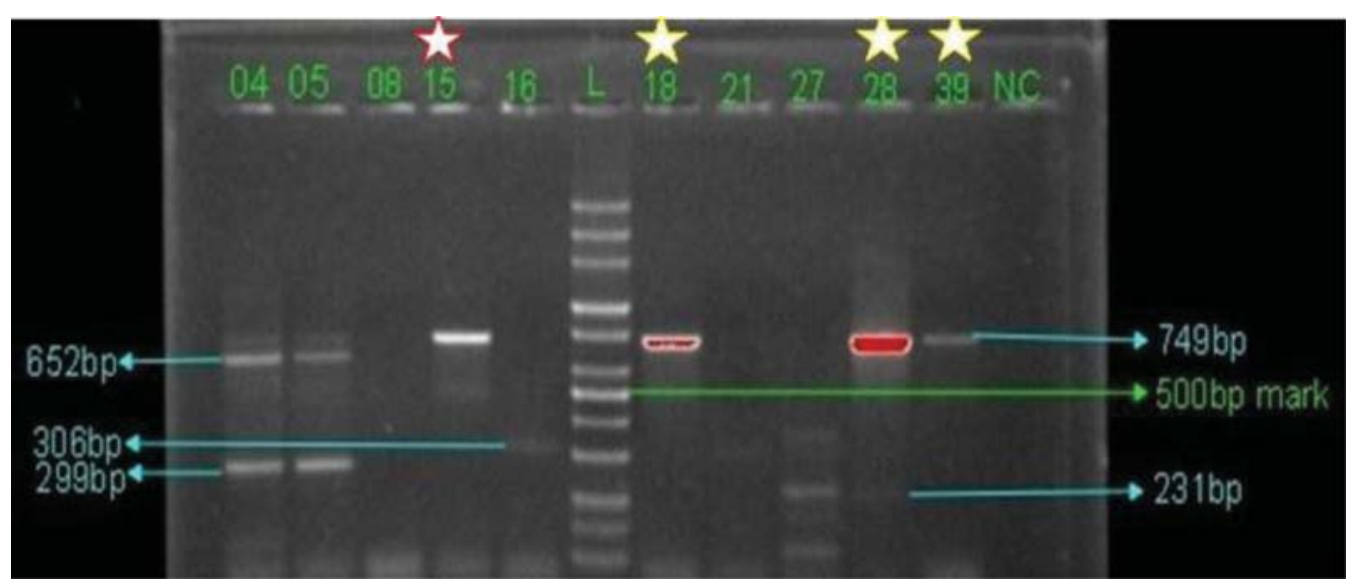

Fig. 2 Gel electropherogram of seminested multiplex polymerase chain reaction products of rotavirus VP7 G-typing, using primer set A for samples 04 (652 bp = G2 and $299 \mathrm{bp}=\mathrm{G} 3$ ), 05 (652 bp = G2 and $299 \mathrm{bp}=\mathrm{G} 3$ ), 08 (nil), 15 (749 bp = G1), 16 (306 bp = G9), 18 (749 bp = G1), 21 (306 bp = G9), 27 (231 bp = G9), 28 (749 bp = G1), 39 (749 bp=G1), and negative control. The mortality case is shown with a red star while other critical cases are indicated by yellow star on top of the respective sample well.

revived. In tandem with the findings of Vesikari et al, $^{29}$ the interval between illness and seeking hospital admission of the child was prolonged and may have thus contributed to severity of the outcome. Of all arrays of genotype specific primers used, the virulent specimens (strains) were G1 strain while the VP4 P-genotype revealed P[6].

Sequencing confirmation and homology of the VP7 gene of the G1 virulent strain and sequence homology between 


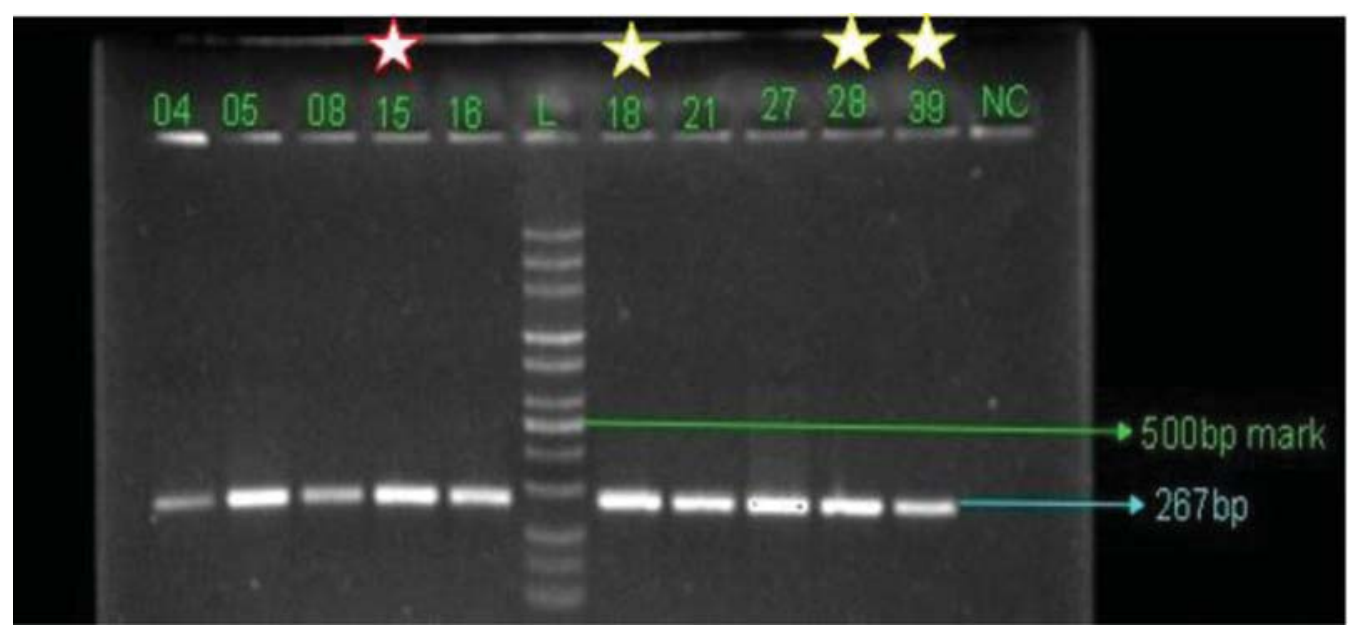

Fig. 3 Gel electropherogram of seminested multiplex polymerase chain reaction products of rotavirus VP4 P-typing showing 267 bp depicting P [6] genotype, using primer set C for samples $04,05,08,15$ (the mortality case), 16, 18, 21, 27, 28, 39, and negative control. The mortality case is shown with a red star while other critical cases are indicated by yellow star on top of the respective sample well.

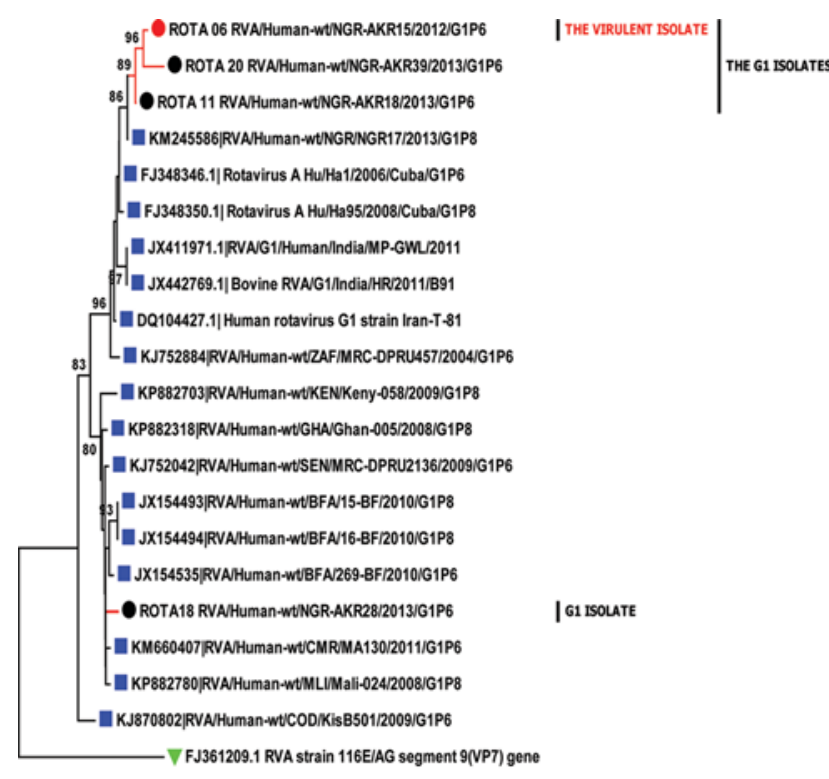

$\stackrel{\longmapsto}{0.02}$

Fig. 4 Phylogenetic tree of nucleotide sequences of VP7 gene of the isolated virulent G1 strains of human rotavirus and the reference strains. The tree was constructed by the neighbor-joining method using ClustalW. The bootstrap values ( 1,000 replicates) supporting each node are indicated. Scale bars corresponds to 0.02

substitutions/site. References in blue squares and GenBank accession numbers for the sequences used in the gene comparisons are indicated in the dendrogram, rooted with an outgroup in lime triangle. The mortality virulent strain is shown in red, while other virulent strains analyzed in this study are shown in black-filled circles.

the mortality virulent strain (RVA/Human-wt/NGR-AKR15/ 2012/G1P[6]) and other G1 strains in this study was high (97-99\%) as it clustered in lineage IV alongside Cuba, India, and Iran but closely related to a previous G1P[8] Nigerian isolate reported in year 2013 (87\% nucleotide identity). While the virulent study strain carried a VP4 P[6] specificity, the previously reported Nigerian 2013 related strain was of common P[8] genotype. The observed difference in the VP4 genotype may be attributed to interspecies transmission,

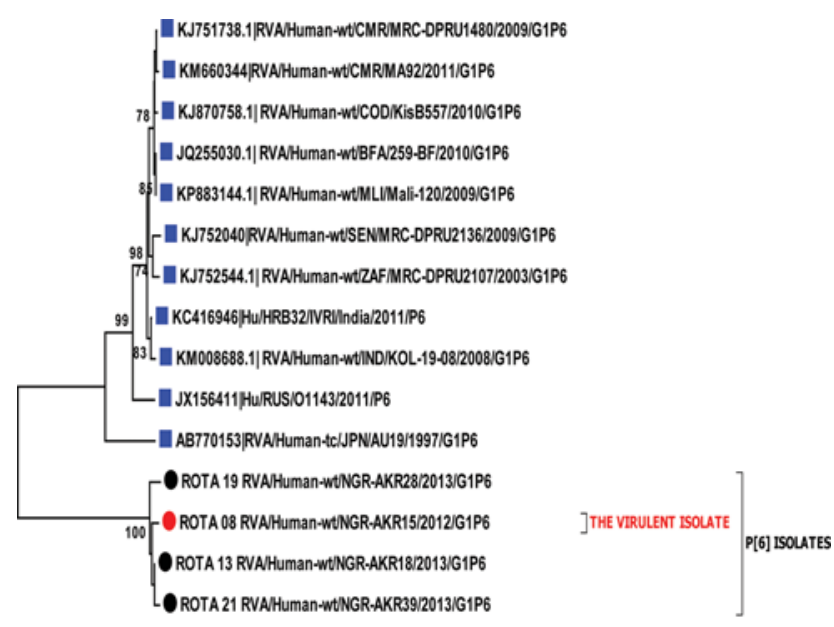

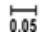

Fig. 5 Phylogenetic tree of nucleotide sequences of VP4 gene of the isolated virulent $P[6]$ strains of the human rotavirus and the reference strains. The tree was constructed by the neighbor-joining method using ClustalW. The bootstrap values ( 1,000 replicates) supporting each node are indicated. Scale bars corresponds to 0.05 substitutions/site. Reference strains and GenBank accession numbers for the sequences used in the gene comparisons are indicated in the dendrogram. The mortality virulent strain is shown in red, while other virulent strains analyzed in this study are shown in black-filled circles.

reassortment or recombination with animal strain as the G1P [6] strain had been acclaimed as an emerging potential zoonotic strain of porcine origin that may critically challenge the effectiveness of oral rotavirus vaccines. ${ }^{30,31}$ Similarly, the virulent isolate had a $95 \%$ nucleotide identity to another isolate RVA/Human-wt/NGR-AKR39/2013/G1P6 that circulated in year 2013 during this study period and was similarly associated with severe diarrhea, dehydration, and comatose in the respondent, thus suggesting the introduction of a single G1 VP7 gene into the RV population in the locality via single source.

Similarly, sequencing confirmation of the VP4 gene of the P[6] virulent mortality strain RVA/human-wt/NGR-AKR15/ 
2012/G1P[6] and phylogenetic analysis were done to determine their relationships to previously reported strains. The sequence homology between the mortality virulent strain (RVA/human-wt/NGR-AKR15/2012/G1P[6]) and other P[6] strains in the study was high $(83-85 \%)$ as it clustered in lineage II alongside Japan and Russia, but somewhat related to P[6] strain from Japan ( $83 \%$ nucleotide identical), than India or Burkina Faso.

Previous studies have ascribed oral vaccine failures to the presence of enterovirus associated EED widely reported in $80 \%$ of Bangladeshi infants with severe unresolved rotavirus diarrhea and mortality even after rotavirus vaccination., Among other patients that had similar sequelae in this study, only in the mortality case was enterovirus found, although testing for biomarkers of EED was not done. In tandem with the previous report, ${ }^{7}$ it is speculated that enterovirus coinfection with rotavirus may have amplified this chronic inflammatory intestinal disease called EED, and the severe dehydration possibly synergized the rapid death of the patient.

\section{Conclusion}

The first single study that established the involvement of a particular RVA strain associated with the mortality of a child is reported here. Rotavirus strain G1P[6] was the virulent etiology of diarrhea that was identified in case fatalities of a cohort of diarrheic children and mortality of a Nigerian female infant in 2012 during episodes of rotaviral diarrhea disease. Based on the isolation of similar P[6] specificity from other patients with comatose sequelae in the study, it is postulated that, if the currently approved rotavirus vaccines (Rotarix and Rotateq containing G1 but not the P[6]) were administered in this region, the vaccine may fare badly against the prevailing serotypes, as it may not proffer cross reactive immunity. Consistent with the virulence of the $P[6]$ genotype and the mortality obtained, a larger epidemiological study that specifically focuses on mortality associated with the $\mathrm{P}[6]$ is hereby advocated to substantiate the need for urgent review of the rotavirus vaccines, and inclusion of the $P$ [6] specificity as a candidate vaccine genotype.

A paradigm shift focusing on rotavirus coinfection with enterovirus in infantile diarrhea disease and presence of biomarkers of EED should be closely monitored in Nigeria. Parents and caregivers are advised to promptly seek medical care as soon as they notice diarrhea of any sort in their children.

\section{Funding \\ None.}

\section{Conflict of Interest \\ None declared.}

\section{Acknowledgments}

All the children who participated in this study and the parents who accented to the study are highly appreciated. Author is thankful to the Hospital Management for the study approval, as we acknowledge the support of Dr. Noel, Dr. (Mrs) Olubosede, Dr. (Mrs) Akeredolu, Dr. Oni, the Nurses, and members of staff at the Children Emergency Ward of the State Specialists Hospital Akure, Nigeria. Author deeply appreciates the mentorship of Professors D.O. Olaleye and Georgina Odaibo of the Department of Virology, University of Ibadan, as author acknowledges the support of Dr. (Mrs) Adedayo Faneye and Mr B.A. Olusola. This study was not funded by any organization.

\section{References}

1 WHO. Under-five mortality. Global Health Observatory (GHO) data. Available at https://www.who.int/gho/child_health/mortality/mortality_under_five/en/. Accessed 2017

2 Platts-Mills JA, Liu J, Rogawski ET, et al; MAL-ED Network Investigators. Use of quantitative molecular diagnostic methods to assess the aetiology, burden, and clinical characteristics of diarrhoea in children in low-resource settings: a reanalysis of the MAL-ED cohort study. Lancet Glob Health 2018;6(12): e1309-e1318

3 Troeger C, Khalil IA, Rao PC, et al. Rotavirus vaccination and the global burden of rotavirus diarrhea among children younger than 5 years. JAMA Pediatr 2018;172(10):958-965

4 Tate JE, Burton AH, Boschi-Pinto C, Steele AD, Duque J, Parashar UDWHO-coordinated Global Rotavirus Surveillance Network. 2008 estimate of worldwide rotavirus-associated mortality in children younger than 5 years before the introduction of universal rotavirus vaccination programmes: a systematic review and meta-analysis. Lancet Infect Dis 2012;12(02):136-141

5 Parashar UD, Hummelman EG, Bresee JS, Miller MA, Glass RI. Global illness and deaths caused by rotavirus disease in children. Emerg Infect Dis 2003;9(05):565-572

6 Parashar UD, Gibson CJ, Bresee JS, Glass RI. Rotavirus and severe childhood diarrhea. Emerg Infect Dis 2006;12(02):304-306

7 Taniguchi M, Platts-Mills JA, Begum S, et al. Impact of enterovirus and other enteric pathogens on oral polio and rotavirus vaccine performance in Bangladeshi infants. Vaccine 2016;34(27): 3068-3075

8 Parker EPK, Ramani S, Lopman BA, et al. Causes of impaired oral vaccine efficacy in developing countries. Future Microbiol 2018; 13:97-118

9 Ramakrishnan G, Ma JZ, Haque R, Petri WA Jr. Rotavirus vaccine protection in low-income and middle-income countries. Lancet Infect Dis 2019;19(07):673-674

10 Tate JE, Burton AH, Bosch-Pinto C, Parashar UD. World Health Organization- coordinated global rotavirus surveillance network: global, regional, and national estimates of rotavirus mortality in children. Clin Infect Dis 2016;62(S2):S96-S105

11 Abiodun PO. Incidence of Rotavirus in acute childhood diarrhea in University of Benin Teaching Hospital. Nig J of Ped 1989; 16:31-34

12 Tagbo BN, Chukwubike C, Mwenda JM, et al, ICH UNTH Enugu Rotavirus Group. Molecular characterization of rotavirus strains circulating in enugu Nigeria: 2011 to 2016. World Journal of Vaccines 2019;9:22-36

13 Pennap G, Peenze I, De Beer M, et al; Kwaga JKP. VP6 subgroup and VP7 serotype of human rotavirus in Zaria, northern Nigeria. J Trop Pediatr 2000;46(06):344-347

14 Audu R, Omilabu SA, de Beer M, Peenze I, Steele AD. Diversity of human rotavirus VP6, VP7, and VP4 in Lagos State, Nigeria. J Health Popul Nutr 2002;20(01):59-64

15 Steele AD, Nimzing L, Peenze I, et al. Circulation of the novel G9 and G8 rotavirus strains in Nigeria in 1998/1999. J Med Virol 2002;67(04):608-612 
16 Japhet MO, Adesina AO, Famurewa O, Svensson L, Nordgren J. Molecular epidemiology of rotavirus and norovirus in Ile-Ife, Nigeria: high prevalence of G12P[8] rotavirus strains and detection of a rare norovirus genotype. J Med Virol 2012;84(09): 1489-1496

17 Alkali BR, Daneji AI, Magaji AA, Bilbis LS. Clinical symptoms of human rotavirus infection observed in children in Sokoto, Nigeria. Adv Virol 2015;2015:890957

18 Ayolabi Cl. Genetic diversity of rotavirus strains in children with diarrhea in Lagos, Nigeria. Asian Pac J Trop Dis 2016;6(07): $517-520$

19 Uzoma EB, Chukwubuikem C, Omoyibo E, Tagbo O. Rota virus genotypes and the clinical severity of diarrhoea among children under 5 years of age. Niger Postgrad Med J 2016;23(01):1-5

20 Babalola MO, Odaibo GN, Olaleye OD, Alonge AO. Enteric adenovirus and norovirus gastroenteritis among under- 5 years children in Owo, Ondo State, Nigeria. Br J Med Med Res 2015;9(08):1-9

21 Durmaz R, Kalaycioglu AT, Acar S, et al; Turkish Rotavirus Surveillance Network. Prevalence of rotavirus genotypes in children younger than 5 years of age before the introduction of a universal rotavirus vaccination program: report of rotavirus surveillance in Turkey. PLoS ONE 2014;9(12):e113674

22 World Health Organization. Manual of rotavirus detection and characterization methods. WHO Document Production ServicesGeneva, Switzerland; WHO/IVB/ 08.17. 1-147. Available at: www.who.int/vaccines-documents/. Accessed 2009

23 Fischer TK, Gentsch JR. Rotavirus typing methods and algorithms. Rev Med Virol 2004;14(02):71-82
24 Gouvea V, Glass RI, Woods P, et al. Polymerase chain reaction amplification and typing of rotavirus nucleic acid from stool specimens. J Clin Microbiol 1990;28(02):276-282

25 Iturriza Gómara M, Kang G, Mammen A, et al. Characterization of G10P[11] rotaviruses causing acute gastroenteritis in neonates and infants in Vellore, India. J Clin Microbiol 2004;42(06): 2541-2547

26 Gentsch JR, Glass RI, Woods P, et al. Identification of group A rotavirus gene 4 types by polymerase chain reaction. J Clin Microbiol 1992;30(06):1365-1373

27 Tamura K, Stecher G, Peterson D, Filipski A, Kumar S. MEGA6: molecular evolutionary genetics analysis version 6.0. Mol Biol Evol 2013;30(12):2725-2729

28 Kawamura Y, Miura H, Mori Y, et al. Three infants with rotavirus gastroenteritis complicated by severe gastrointestinal bleeding. J Med Virol 2016;88(01):171-174

29 Vesikari T, Karvonen A, Prymula R, et al. Efficacy of human rotavirus vaccine against rotavirus gastroenteritis during the first 2 years of life in European infants: randomised, double-blind controlled study. Lancet 2007;370(9601):1757-1763

30 Iturriza-Gómara M, Dallman T, Bányai K, et al. Rotavirus surveillance in europe, 2005-2008: web-enabled reporting and realtime analysis of genotyping and epidemiological data. J Infect Dis 2009;200(Suppl 1):S215-S221

31 Ruiz-Palacios GM, Pérez-Schael I, Velázquez FR, et al; Human Rotavirus Vaccine Study Group. Safety and efficacy of an attenuated vaccine against severe rotavirus gastroenteritis. N Engl J Med 2006;354(01):11-22 